\title{
Influence of Journalist Knowledge about Gender Mainstreaming Ideology on the Reporting of Gender Issues
}

\author{
Nkem Fab-Ukozor \\ Department of Mass Communication, Imo State University, Owerri, Nigeria \\ Email: fabukozor2000@yahoo.com
}

How to cite this paper: Fab-Ukozor, N. (2019). Influence of Journalist Knowledge about Gender Mainstreaming Ideology on the Reporting of Gender Issues. Advances in Applied Sociology, 9, 269-287. https://doi.org/10.4236/aasoci.2019.97021

Received: May 6, 2019

Accepted: July 5, 2019

Published: July 8, 2019

Copyright $\odot 2019$ by author(s) and Scientific Research Publishing Inc. This work is licensed under the Creative Commons Attribution International License (CC BY 4.0).

http://creativecommons.org/licenses/by/4.0/

Open Access

\begin{abstract}
Democracy has universal appeal in its respect for popular participation, accountability, equity and equality. The adoption of gender mainstreaming in Nigeria via the National Economic Empowerment Development strategy in 2003, and recently the 7-point agenda, vision 2020, among other development programmes support democratic values in the sense that the country's ultimate goal is to achieve national development based on gender parity. This study sought to determine the Influence of Journalist Knowledge about Gender Mainstreaming Ideology on the Reporting of Gender Issues. The research which was anchored on the critical cultural theory was necessitated by the need to find out empirically how Nigerian journalists understood gender mainstreaming issues and its implications for their reportage of the issues. The survey research method using questionnaire and semi-structured interviews was adopted in this study. Practicing journalists in Nigeria put at 10,000 made up the study population. The sample size was 500 based on Nwanna's (2008: p. 71) expert recommendation of selecting 5\% of elements or units for a population size of several thousands. Results from the study established that Nigerian journalists have significant knowledge of gender mainstreaming issues which in turn influence the reporting of the phenomenon. Also, the dominant form of reporting of gender mainstreaming issues by journalists' influences their perception of the phenomenon. In view of these findings, the study recommended sensitization of journalists to ensure that journalists begin to appreciate their ethical responsibility towards the cause of gender mainstreaming. Again, there will be need to strengthen advocacy and also move beyond the media organizations to media associations, since they are the umbrella body that can take decisions worthy of influencing media and editorial policies which, can facilitate gender sensitive and balanced reporting.
\end{abstract}




\section{Keywords}

Influence, Gender, Gender Mainstreaming, Reporting, Journalists, Nigeria

\section{Introduction}

Most media and gender activities seem to agree that the mass media are not just mirroring society but are encouraging gender inequality through the promotion of stereotypes and the stigmatization of certain groups of people, particularly women, hence the inclusion of the introductory statement to section J: "Everywhere the potential exists for the media to make a far greater contribution to the advancement of women" (cited in Gallagher, 2005: p. 4). Thus, one can conclude that the media plays a fundamental role in the perpetuation of unequal gender relations at all levels of society, Gallagher (2005: p. 3).

Therefore, the issue is that media and gender advocates perceive the media as a tool that can be used for women empowerment, without considering the fact that those who work in the mass media are still part and parcel of a cultural system that encourages unequal gender relations. This can be attributed to many gender activists who hold limited instrumental view of the role of media in the context of women's rights agenda, Gallagher (2005).

It was for this reason that the World Association for Christian Communication (WACC) had in 1995 pioneered an international study known as the Global Media Monitoring Project (GMMP) aimed at probing the extent and pattern of women's and men's representation in the news, having observed the serious lack of attention to women issues in almost every society. The study has since then been held every five years, and the findings have consistently shown that women are poorly represented, and do not receive attention as subjects of news like their male counterparts. Since WACC started this project, the results have been useful in illustrating global patterns in news content, highlighting the persistent poor presence of women in national news media, and initiating dialogue between media advocates and media practitioners, among other things.

Above all, GMMP has remained a platform for change starting from grassroots to policy-making circles and is thus recognized by the United Nations (UN) after the first GMMP which was coordinated by Media Watch Canada in 1995. The final report entitled Women's Participation in the News which showed a very poor representation of women was released the same year at the fourth UN World Conference on women in Beijing. Consequently, "women and the media" was included in Section J, and media monitoring of women's roles and representation became part of the platform resolutions. However, the fourth phase of GMMP was held on November 10, 2009 instead of in 2010, in order to feed into two key global processes: the 15-year review of the progress made in implementing the Beijing Platform for Action for the Advancement of Women held in March, 2010; and, the Millennium Development Goals (MDGs) summit 
held in September, 2010 (GMMP, 2010).

Although the poor representation of women in the mass media is directly related to the marginalization and subjugation of women in the society, gender as is wrongly assumed does not refer to women alone. It was basically this misconception that necessitated the shift in emphasis from the Women in Development (WID) approach that dominated discourses and interventions during the International Decade for Women (1975-1985) to the GAD approach which came into popular usage with the adoption of the Beijing Declaration and Platform for Action (BPFA) as earlier stated. Since then, the focus has shifted from targeting only women for development projects to gender analysis of women's and men's roles and impact of interventions on women and men as part of the planning process of all development initiatives and to gender equality as a goal of development (Akpalu et al., 2000: p. 14).

Thus, gender mainstreaming, as a term gained popular or widespread usage with the shift to GAD approach following the Beijing Declaration and Platform for Action. It recognizes the fact that to achieve meaningful progress in the advancement of women, and the society at large, there was need for a more fundamental change in mainstream policies and resources allocations to reflect the interests and views of women as well as men.

In response to the GAD approach, media practitioners are therefore expected to report gender related issues and occurrences from a gender perspective. This pattern of reporting also requires that the process of gathering, packaging and disseminating gender related information should be based on journalistic principles of accuracy, objectivity, balance and fairness to all gender categories. It calls for gender sensitivity in the choice of what to cover or report, how to cover or report, the choice of language of delivery and images to be associated with the coverage. Most importantly, journalists owe it as a responsibility to protect the basic human rights of women based on ethical principles of the profession, democratic values, and the right to communicate including the right to media access as earlier stated. The principles of journalism categorically stated as watchdog function brings to bear the need to report issues and occurrences with the maximum assurance of accuracy, fairness and balanced representation free from all biases, including gender.

This may sound too simplistic. But recognizing the impact of socialization and realizing too, that it is difficult to separate oneself from the cognitive processes that run through the mind which in effect determine the perception of issues in any environment, it becomes pertinent to reason that before journalists can effectively achieve success in the task of shaping gender realities of the moment, there was need for them to primarily change their mindsets and attitudes in favour of women rights agenda.

Over the years, men and women in most societies, including Nigeria, have been socialized into believing certain misconceptions about gender values and norms to be right and "which for most people have become the proper way that things should be done (emphasis mine) without question" (Made, 2004: p. 
50). In a sense, this attitudinal pattern has given rise to gender biases which nevertheless influence the way most people do their work; and in the mass media are a powerful form of censorship. For instance, in choosing news sources, both men and women reporters seem to have been socialized to believe that only men are leaders and so should be spokespersons even when women occupy superior or similar positions.

However, inasmuch as those gender biases are natural and could act as internal factors in censoring media content to the disadvantage of women, professional call to duty overrides such human tendencies. Moreover, the UN and several non-governmental bodies have made huge commitments to the training of journalist in different parts of the world in order to equip them with requisite knowledge concerning gender and development issues. Such workshops have taken place at national, regional and international levels, especially since after the ratification of the Convention on the Elimination of all forms of Discrimination Against Women (CEDAW) by UN in 1979 and which Nigerian government adopted in 1984. In Nigeria for instance, the Media and Gender Enlightenment Initiative (MEGEIN) in collaboration with WACC had held gender perspective training workshops for senior journalists in the six geo-political zones of the country from December, 2008-May, 2009 (Vanguard, May 26, 2009).

Nevertheless, a major step towards the attainment of the goal of equal rights for women was taken on 18 December 1979, when the General Assembly of the United Nations adopted the Convention on the Elimination of All Forms of Discrimination against Women (CEDAW). The 30-article convention sets out in legally binding form internationally accepted principles and measures to achieve equal rights for women everywhere. The comprehensive convention reflects the depth of the exclusion and restriction practised against women solely on the basis of their sex, by calling for equal rights for women, regardless of their marital status, in all fields. It calls for national legislation to ban discrimination; recommends temporary special measures to speed equality in fact between men and women, and action to modify social and cultural patterns that perpetuate discrimination (see Appendix X, Passport to Equality, 1999). Meanwhile, there are plans to make the convention part of the national legislation in Nigeria having articulated a bill in that direction at the national assembly; though the process seems to have stagnated.

Undoubtedly, women constitute the majority of the poor in Africa, and indeed Nigeria (Oji, 2008). Moreso, the facts of women discrimination and subjugation are no longer debatable. And since Nigeria has initiated some development programmes such as National Economic Empowerment Development strategy (NEEDS) at the three tiers of Government aimed at improving the social conditions of the marginalized populations and the 7-point agenda (power and energy, food security and agriculture, wealth creation and employment, transport, land reforms, security and education) equally targeted at addressing the inherent problems that have kept majority of its populations in chains of poverty, it becomes pertinent to methodically study the extent to which reporters in 
the country understand the meaning and implications of gender mainstreaming in their work.

By way of stating the research problem, this study, therefore, becomes imperative because there is the need to find out empirically how Nigerian journalists understand gender mainstreaming issues and its implications for their reportage of the issues. The study therefore sought to find out the knowledge level of Nigerian journalists on gender mainstreaming issues; examine the extent to which the dominant form of coverage of gender mainstreaming issues by the journalists influence their perception of the phenomenon; and find out the extent to which journalists' knowledge about gender mainstreaming ideology influences their reporting of the phenomenon.

\section{Theoretical Background}

\subsection{Media Access and Communication Rights: A Gender and Social Justice Perspective}

The deprivation of basic human rights in most nations has posed serious threats to the attainment of democratic governance, particularly in the developing world of Africa, of which Nigeria is part. Of all the rights that comprise fundamental human rights, communication rights of people seem to be most abused in all societies, though it is worse in Africa, including Nigeria. This informs why no nation can actually boast of an ideal democracy (MacBride, 1980: p. 166).

Majority of the population in Africa are poor and hungry and about $80 \%$ of them dwell in the rural areas. They have little or no access to portable water, electricity, health care delivery, education, and worse of it all, the media. It is so stated because the media are expected to highlight crucial issues, which affect the lives of majority of people and make government accountable. This category of people, made up of mostly women, youths and men of low income do not have access to the media as earlier cited according to research evidence, hence issues that affect their lives are less likely to be part of public agenda. Rather, the common observation is that the views and opinions of the few elites who have access to the media dominate and represent the views and opinions of the public. The import therefore, is that prominence as a criterion of news judgment is seemingly taking the place of consequence, which by journalistic principles and standards is considered as the most important news value. This is against justice and democratic principles and counteracts the expectations of the mass media by the citizens of any democratic society. Truly speaking, if media actually protect public interest, the government in most cases will be held accountable for their actions and inactions particularly as it concerns human rights abuses. Most governments are interested in their public image and would not like the media to expose them to public criticisms or sanctions from world bodies. The Amnesty International Manual (1997) cited in Lee (2006: p. 35) says this much when it posits that no government likes domestic or international criticism. With regard to human rights, the media can play a key role in building awareness and 
shaping public opinion on human rights and related issues; shape the framework and nature of debates over important issues affecting human rights, not least the death penalty or human rights in foreign policy; generate action from its audience; influence government policy, both directly and through its power to influence and mobilize opinion; put direct pressure on a government by placing it in the spotlight; help build the morale and influence of human rights activists and organizations all over the world; investigate and expose human rights issues.

The above views explain why most experts agree that a relationship exists between poverty and communication (Mohr, 2008; Tacchi, 2008; Omenugha \& Adum, 2008). This is because the ability of any human group to contribute through communication to the creation and exchange of socially shared meanings is pertinent to creating a world that responds to their needs. Oftentimes, this kind of involvement or level of expression seems to be lacking in Nigerian society, meaning that the poor does not have a voice, particularly when it concerns development. According to Tacchi (2008: p. 12), voice in this context "can be defined as inclusion and participation in social, political and economic processes, meaning making, autonomy and expression". Therefore, greater percentage of the population in African region suffer from 'voice poverty', which Tacchi (2008: 12) refers to "as the denial of the right of people to influence the decisions that affect their lives, and the right to participate in that decision making". This ugly situation is partly caused by the selfish desire of politicians or business conglomerates who "aim to gain or maintain power so as to continue to control, influence or restrict public communication by direct or indirect means to win support or compliance" (Mohr, 2008: p. 8). It is no gain stating the obvious, that the few powerful and privileged citizens have greater access to and influence over public communication processes than those living in poverty such as women, youths and ordinary men.

Communication inequality is a crucial component of poverty and social injustice that needs greater attention in contemporary thinking about social stability and national development. If public communication (i.e. the mainstream media comprising newspapers, magazines, radio and television) does not address problems and issues affecting poor people, "those invisibilised' concerns in effect do not exist in that society's public agenda" (Mohr, 2008: p. 10). And if the trend continues, the problems will never be solved, because the society does not know about them or rather does not consider the issues important. The news media are particularly powerful because they are our principal source of information about what is happening in the world, yet they do not simply offer a "window on the world". They routinely decide what information we should receive, what news we should watch, hear and read. In doing so, the news media influence our beliefs, attitudes and standards, so that our idea of who we and others are, as female and male is influenced by media messages (Who Makes The News, 2005). By constantly portraying women as second-class citizens, as objects, and as helpless victims of the all-powerful, oppressive partriachy system, a certain image of men is created as insensitive, wicked and uncanny group of people, which 
does not augur well for societal growth.

However, it becomes pertinent to also point out that the media do not as well give access to all categories of men. There seems to be discrimination or marginalization in terms of excluding the voices of men that are ordinary or poor. In corroboration of this view, Baber (cited in Goldberg, 2002) asks; who has spoken boldly about men's rights?... who has represented us on the presidential stump in the areas of divorce, child custody, abortion, military-draft registration, false accusations of rape, high unemployment for both young and old men, male longevity and health?... if the big-time media elites weren't such feminists themselves, or afraid of offending them, they might have done some fresh, interesting stories on a whole range of gender issues instead of the old "safe clichés".

It was for this reason that the United Nations Decade for Women, which began in 1975 noted the media as playing a fundamental role in the perpetuation of unequal gender relations at all levels of society. And with the shift in emphasis to gender and development, the Beijing Platform for Action in 1995, had in addition identified "women and the media" as one of the 12 critical Areas of concern (UN’s Press Release, 2005), as earlier noted. Ever since then, media and gender advocates have expected the media to give sensitive coverage to gender issues particularly as they are related to national development, not realizing it is important to engender the media before such high expectations. Editors, reporters, journalists and media owners are extensions of the society; hence their mindsets are controlled by its cultural norms and values, which invariably create the internal biases and prejudices that influence the choices which they make in providing access and expressions to citizens. Rather, priority was given more to the employment patterns of women and men, especially in media management, than to the influence of gender biases on newsgathering and other media practices and processes (Made, 2004: pp. 49-50).

\subsection{The Global Media Monitoring Project (GMMP)}

The GMMP is the world's longest running and most extensive research on gender in the news media. The project which takes place every five years began in 1995 when volunteers in seventy-one countries, including Nigeria monitored women's presence in their national radio, television and print news. The research design is content analysis hence, each participating country is assigned a specific number of newspapers and radio and television newscasts to monitor based on the national media density. This is done to ensure that global results would reliably reflect the distribution of the world's news media, while respecting the need to balance results from smaller countries with those of larger countries. The number and selection of media outlets monitored in each country reflects the density and diversity-audience, ownership, language of media in each country (Macharia, 2010). As earlier stated, GMMP 1995 revealed that 17 percent of news subjects were women, while 83 per cent were men. (GMMP, 2000: p. 5). Also 59 per cent of men were announcers and reporters in the mass media, while 41 per cent were women. 
The third GMMP in 2005 attracted the participation of 76 countries. Some progress in women's presence in the news was evident. 21 per cent of news subjects according to the Global Report (2005) were female, while 79 per cent were male. This 3 per cent increase in the preceding five years was statistically significant. However, the overwhelming finding was women's continued near invisibility in the news. Very little news-just under 10 per cent of all stories-focused specifically on women, the Report (2005) added. Further findings show that women were rarely central in stories that comprised the bulk of the news agenda. Also, women were outnumbered by men as newsmakers in every major news topic.

\subsection{Gender and Communication in Nigeria}

In studying the situation of gender and communication in Nigeria, Okunna (2002) used four news magazines (Newswatch, Tell, The News and The Week) together with five newspapers (The Guardian, Post Express, Champion, Vanguard, and Daily Times) as sample for the study. A purposeful decision she made to limit the study to the lead stories as featured on the cover of the magazines led to the selection of a total of 42 stories from four issues of each of the magazines published in January and February 2002. Similarly, a total of 566 stories in the major news pages of the newspapers published in May 2002 were equally selected. The stories were content analyzed "in terms of text and pictures to ascertain women's participation in the news as news subjects and journalists" (Okunna, 2002) using the GMMP 2000 media monitoring format, Hence, Okunna (2002) came up with the following findings:

- Packaging of news is still men's work' in Nigeria. Of the 101 reporters whose bylines appear in the 42 news magazine stories, 92 (91\%) were male while a very low $9 \%$ were female. Nevertheless, as low as this figure is, it represents a slight improvement on the GMMP 2000 figure of 5\% participation of women as news reporters in Nigeria's mass media.

- In terms of people in the news, women are equally invisible, as the findings show a very low participation of women in news making. The fact that women make up at least $50 \%$ of Nigeria's population is not reflected in the number of women who make news in the mass media. In news magazines, a disproportionate $86 \%$ of people in the news are male, while women accounted for a mere 14\%. 675 people appeared in the 42 news stories, 581 of them were men. Women's invisibility in the news is also reflected in newspaper coverage. Only 93 (16\%) of the 566 news stories involve women, and only 53 of these have women as their central focus.

- In addition to not being given prominence in terms of frequency of appearance, women are also denied prominence in being quoted and seen in photographs. A total of 61 photographs appear on the covers of the news magazines used in this study; a mere $10 \%$ or 6 photographs are of women. Similarly, out of the 263 photos which accompany the full news reports, only 30 (11\%) are photos of women. The situation is the same in newspapers where 
women are hardly quoted and their photographs are rarely used in news stories.

\section{Theoretical Framework}

To help in the understanding of this study, the cultural theories were adopted. A set of theories (including symbolic interaction, social construction of reality, cultivation analysis and critical cultural theory), known as cultural theories were developed by mass communication theorists after observing the overwhelming impact of the television on its audience, particularly with the emergence of new communication technologies such as the cable satellite and computer networks. Most of the theorists (DeFleur, D'Antonio, DeFleur, 1971: p. 165) arrived at the conclusion that by emphasizing certain topics, stressing particular interpretations or overusing specific themes (it is hypothesized), the media may create the distorted impression that their "definition"-or set of norms-is a reflection of the real society.

Of particular relevance to this study is the critical cultural theory hinged on "the idea that media operate primarily to justify and support the status quo at the expense of ordinary people" (Baran, 2009: p. 430). Needless to emphasize that women who are taken as second class citizens in all cultures including Nigeria, could be categorized as the ordinary people in this context. Meanwhile, the critical cultural perspective, which is solidly rooted in neo-Marxist theory, emerged in the United States in the 1930s, following the escape of two prominent media scholars (Theodore Adomo and Max Horkheimer) of university of Frankfurt, from Hitler's Germany. While the "old fashioned" Marxists believed that people were oppressed by those who owned the factories and the land (the means of production), the modern neo-Marxist theorists believe that people are oppressed by those who control the culture, the superstructure-in other words, the mass media (Baran, 2009: p. 430). It is Baran's (2009:430) view therefore that the critical cultural perspective which is "centered in neo-Marxism ... saw consumption of art as a means to elevate all people toward a better life". Continuing, he said that "typical media fare-popular music, slapstick radio, and movie comedies, the soft news dominant in newspapers pacified ordinary people while assisting in their repression. It is no gain stating the obvious fact that Nigerian media also give support to the socio-cultural system, which subjugate and marginalize the female folk.

Nevertheless, several conceptions of the relationship between media and culture are attributed to the critical cultural theory. These conceptions according to Baran (2009: p. 430) share identifying characteristics as follows:

- They tend to be macroscopic in Scope. They examine broad, culture wide media effects.

- They are openly and avowedly political. Based on neo-Marxism, their orientation is from the political left.

- Their goal is at the least to instigate change in government media policies; at the most, to effect wholesale change in media and cultural sys- 
tems. Critical cultural theories logically assume that the superstructure, which favours those in power, must be altered.

- They investigate and explain how elites use media to maintain their positions of privilege and power. Issues such as media ownership, government-media relations, and corporate media representations of labour and disenfranchised groups are typical topics of study for critical cultural theory because they center on the exercise of power.

\section{Methodology}

The survey research method was adopted in this study. It was aimed at producing an accurate picture of the population from where the sample would be chosen. "Surveys allow researchers to measure characteristics, opinions, or behaviours of a population by studying a small sample from that group, ..." (Baran, 2009: p. 350 ), hence its usage in the study. The population of registered practicing journalists in Nigeria as at the time of study was 10,000 (NUJ, Newsletter, 2010), and it is as indicated in the table below. In determining the sample size, Nwanna's (2008: p. 71) expert recommendation of selecting 5\% of elements or units for a population size of several thousand was used, and 500 was obtained.

To get the needed sample size, a number of steps were taken as follows:

Step one

In this process, the researcher arranged the state population of the journalists in clusters, representing the Abuja-the Federal Capital Territory (FCT), which is a special interest area, being the nation's capital and the six geopolitical zones of Nigeria namely, North East, North West, North Central, South East, South West and South-South.

\section{Step two}

Under this step, the population of the journalists in each zone was stratified according to the two gender types (female (f) and male $(\mathrm{m})$ ). This was done to ensure fair representation of gender types, given that the study is based on gender mainstreaming. The stratifications are as shown in Table 1.

Table 1. Gender Stratification of Journalists in the Zones.

\begin{tabular}{ccccc}
\hline \multirow{2}{*}{ S/No } & Zone/FCT & \multicolumn{2}{c}{ Gender Spread of population } & \multirow{2}{*}{ Total Population } \\
\cline { 3 - 4 } & & F & M & 1295 \\
\hline 1 & FCT & 205 & 1090 & 525 \\
2 & North East & 145 & 380 & 975 \\
3 & North West & 180 & 795 & 960 \\
4 & North Central & 160 & 800 & 940 \\
5 & South East & 280 & 660 & 4100 \\
6 & South West & 1115 & 2985 & 1205 \\
7 & South South & 300 & 905 & 10,000 \\
Total & & & &
\end{tabular}

Source: Field Survey, 2010. 


\section{Step three}

Having estimated the desirable sample size of the total population to be 500 , the number of journalists to be drawn from each geopolitical zone is therefore calculated by multiplying the population of each gender stratum in each zone by 500 and dividing by 10,000 which, is the totality of the parent population. The table below shows the computed sample sizes for the zones according to their gender strata.

The researcher used questionnaire and semi-structured interviews to obtain data for the study. The questionnaire was used to gather data from the respondents regarding their demographic, psychographic and behaviouristic variables, while the semi-structured interview afforded the opportunity of adding more depth from the respondents that were not administered the questionnaire.

In validating the test instruments, the researcher took the instruments to five scholars who have sound knowledge in the application of research tools for their invaluable expert criticisms which in essence added value to their quality.

To determine the reliability of the questionnaire, the researcher adopted the external consistency method, which involves comparing the tests of a group at two different periods or comparing two different tests on a group at the same time (Obasi, 1999: p. 126). The test-retest method was applied. The researcher conducted the test using $10 \%$ of the sample size (500 respondents), which is 50 . Therefore, the researcher conducted the test using 50 registered journalists in Abuja. During the first test, the researcher administered the instrument to the respondents with an introductory letter acquainting them with the rationale for the study. The respondents were assured of complete confidentiality of all the information supplied. Moreso, they were allowed to complete the questionnaire at their own convenience. Appointments were booked for the collection by the researcher. The researcher collated the results of the test and conducted a retest after two weeks on the same subsample. All the copies of the questionnaire were retrieved. The result of the retest conducted in period B was correlated with that of period A test, using Pearson's Product Moment formular. The result obtained was 0.81 , which shows a high coefficient of correlation, between the two results. Hence, the instruments were adjudged reliable.

\section{Discussion of Findings}

An appraisal of the results and inferences drawn from this study strongly support the following claims:

- Nigerian journalists have significant knowledge of gender mainstreaming issues.

- Nigerian journalists' knowledge of gender mainstreaming influences the reporting of the phenomenon.

- Nigerian journalists are not favourably disposed towards the ideology of gender mainstreaming reporting.

- The dominant form of reporting of gender mainstreaming issues by journalists' influences their perception of the phenomenon. 
This means that only null hypothesis three was accepted out of the four null hypothesis, thus resulting to the acceptance of the alternates of the other three hypotheses. Hence, the rejection of null hypothesis one at chi-square $\left(\mathrm{x}^{2}\right)$ calculated value of 7.589 which is greater than $\mathrm{x}^{2}$ table value of 3.841 shows that $\mathrm{Ni}$ gerian journalists have meaningful knowledge of gender mainstreaming issues.

Thus, their significant awareness of the current global consensus on gender approach to development (GAD), attest to this knowledge. And if the literature is anything to go by, it means that the journalists know that in responding to gender mainstreaming or GAD, they are expected to report gender related issues or occurrences from a gender perspective. While $89.41 \%$ of the respondents acknowledge that GAD is meant to achieve women empowerment, $62.35 \%$ of them affirmed to the statement that giving attention to women's rights, views and concerns should be the main focus of GAD.

For the avoidance of doubt, result from data collected shows an assessment by the journalists themselves regarding their knowledge of gender mainstreaming issues. Out of the 425 respondents, 325 (76.47\%) agreed that they are knowledgeable of the issues, $75(17.65 \%)$ reacted otherwise, and 25 (5.88\%) were neutral. This confirms that a greater percentage of the respondents are knowledgeable of gender mainstreaming or rather gender perspective reporting. For instance, in reaction to if the call for gender mainstreaming demands the co-operation of the journalists for better gender relation, 407 (95.76\%) of the respondents showed agreement with the statement, as against $13(3.06 \%)$ that disagreed while 5 (1.18\%) remained neutral. A reinforcement of this finding was emphasized by the result which shows majority agreement with the question on if gender insensitivity affects both gender differently. However, results of certain items in the questionnaire indicate the respondent's negative perception of some gender mainstreaming issues. Data show their disagreement with the fact that gender mainstreaming issues are of great importance to Nigeria's development. This finding was reinforced by the result showing that majority of the respondents rejecting the position of the statement that violence against women has the tendency of retarding Nigeria's human political and socio-economic development like NAPEP, NEEDs, SEEDs, LEEDs and a host of others meant to ameliorate subjugation of women in Nigeria. Moreover, results concretizes the negative perception of the respondents by having an overwhelming majority of them disagreeing with the notion that factors like low employment of women in public places, harmful cultural practices against women, preference for male child, girl-child marriage, and trafficking of women increases violence against women.

Nevertheless, further reinforcement of the respondents' positive perception was again showcased by the data where 402 (94.59\%) respondents agreed with the statement that journalists should give equal participation to women and men in their reportage of gender mainstreaming issues; 15 (3.53\%) disagreed, while 25 (5.88\%) were neutral.

More so, rating of the respondents' reaction to the issue of whether discrimi- 
natory cultural practices in Nigeria hinder the realization of gender equity and equality', showed that they are aware of the fact that the issue surrounds the ideology of gender mainstreaming, and again confirmed their positive perception, as the result tilted towards acceptability with the position of the statement rather than rejection.

On the issue, that several cases of injustice, maltreatment, violence and discrimination against the female sex prevail in Nigerian society, the result of the rating equally reveal an agreement with the position of the statement and further confirms their awareness of the issues surrounding gender mainstreaming.

The rating on gender violence and discrimination as critical issues affecting mainstreaming gender in Nigeria, in addition, disclose an overwhelming majority of the respondents tilting towards acceptance with the position of the statement rather than rejection. This finding further concretizes earlier findings of positive understanding and perception.

Majority of the respondents are also of the view that in spite of the improvement in Nigeria's democratic culture, violence against women persist in the country, as the data show agreement with the position of the statement rather than disagreement. Similarly, the result shows their majority agreement with the statement that "the spate of violence against majority of women is on the increase in recent time" further confirms their awareness of the issues surrounding gender mainstreaming in the country. To this end, an overwhelming majority of them realize the fact that the ministry of women affairs was created in Nigeria to enhance the status and welfare of women.

Although the respondents have good understanding of issues surrounding gender mainstreaming as established by the significance test and other results, it is important to note that their negative perception of some of the important issues raised, justify the growing gender disparity and injustice prevailing in Nigerian society, which is negatively affecting gender development as confirmed by sources in the literature review (King cited in Ana, 2008) holds this same view, when he cautions that "equality between women and men is both a human rights issue and a precondition for, and indicator of sustainable people centered development".

Meanwhile, an analysis of the respondents' assessment of the major factor militating against women empowerment, has Nigeria's cultural values that place women in disadvantaged position as the best option by a greater majority of 285 $(67.06 \%)$ of them. Followed by $102(24 \%)$ that opted for limited number of women who should project women's views in the media. While the other choice ranked as follows: Poor knowledge of the importance of gender mainstreaming, opted by - 25 (5.88\%); Journalists' lack of interest in gender mainstreaming issues, chosen by $8(1.88 \%)$, and finally delay in passing the bill of CEDAW as an option by 5 (1.88\%) respondents. This finding further reveals their awareness of the issues surrounding gender mainstreaming which of course is expected, considering their professional exposure, educational level, field of study and age. 5 $(1.18 \%)$ of them have their Ph.D. 185 (43.53\%) have either B.A, B.Sc, B.Ed or 
HND; 168 (39.53\%) have M.A, M.Sc or M.Ed; while only 48 (10.82\%) fall under the category of NCE/OND, 15 (3.53\%) have WASC/GCE/NECO, and $6(1.41 \%)$ with other certificates. More so, a majority of $248(58.35 \%)$ respondents studied mass communication; 95 (22.35\%) have Political Science as their field of study; 24 (5.65\%) read sociology; An equal 20 (4.71\%) respondents studied either history and international relations or any other discipline; 11 (2.58\%) and 7 (1.65\%) respondents respectively have linguistics and law as their fields of study. Equally, majority of them fall under the productive age brackets of 46 - 55 years, yielding $160(37.65 \%)$ respondents; 36 - 45 years have 120 (28.24\%); and 26 - 35 years have $60(14.11 \%)$ respondents. Hence, they are a group of vibrant, well-informed journalists that can respond to the questions in the questionnaire and the SSI.

Meanwhile, an analysis of the journalists assessment of factors which influence their disposition and perception of gender mainstreaming issues has cultural orientation as their major option by 150 (35.29\%) of them; followed by knowledge of gender mainstreaming issues with 125 (29.41\%) respondents; sense of news value judgment with 100 (23.53\%); and ethical orientation with 50 (11.77\%). It is important to note that none of them opted for organizational policy as an influencing factor, which by inference means that mass media organizational policies in Nigeria are gender neutral. This finding goes to support the cultural theories which form a major aspect of the theoretical background. The theories according to Baran (2009: p. 427) say that "meaning and, therefore effects are negotiated by media and audiences as they interact in the culture". In so doing the social and cultural practices that result in the silencing women are echoed and sometimes amplified, by the news media as they write messages that influence our idea of who we are and others are, as female and male.

Similarly, the result showing an analysis of the respondents' assessment of the most involved issues of gender mainstreaming equally has discriminatory cultural practices against women as the major option by 225 (52.94\%) followed by violence against women with 85 (20\%); then affirmative action with 65 (15.29\%); and communication rights with $50(11.77 \%)$. None of them opted for inheritance rights. Again, this finding further reinforces and concretizes the respondents positive understanding of gender mainstreaming issues, and support the notion that journalists are influenced by cultural orientation.

These findings are in conformity with opinions of sources in our literature review, including Made (2004: p. 48), Gallagher (2010: p. 3). Media practitioners do not live in isolation. Gender biases and prejudices have therefore become endemic to the news processes that virtually all news is told through the voices and perspectives of men. Hence, women's personal freedom of expression and democratic right to communicate are curtailed and limited by the media. The above findings apparently justify the position of the literature review in suggesting that Nigerian journalists need continuous sensitization and training workshops and seminar on gender mainstreaming reporting in order to meet up with their present professional demand of reporting gender related issues from a gender perspective. This is necessitated by the ignoble situation of women invisibility 
and misrepresentations which have continued to prevail in the country's media as confirmed by the literature. Therefore ascertaining if journalists' knowledge about gender mainstreaming influences the reportage of the phenomenon becomes imperative.

Thus leading to null hypothesis two stated as Nigerian journalists' knowledge about gender mainstreaming ideology does not influence the reporting of the phenomenon. This hypothesis failed to receive statistical support at 8.62 chi-square $\left(\mathrm{x}^{2}\right)$ calculated value which is greater than table value of 3.841, implying that its alternate was accepted. Moreover, the result give support to the relationship existing between journalists' knowledge and reportage of the issues by confirming the view that there is a relationship between journalists' knowledge of gender mainstreaming issues and their reportage of the issues. However, it is only natural that you can give what you have. And by empirical evidence, too, data confirmed that journalists' who are knowledgeable in gender mainstreaming issues will report the issues better'. Other results in the study equally gave support to the above finding. For instance, data show that a majority of 275 (64.7\%) respondents acknowledge that journalists' knowledge and perception influence to a large extent, gender development in Nigeria, as against 75 (17.65\%) that disagreed. Another 75 (17.65\%) chose to remain neutral.

However, an assessment of respondents' perception of government's interest in gender mainstreaming issues show that they are of the opinion that the government is not genuinely interested, as revealed by data from the questionnaire. It could therefore be inferred that their lack of commitment to the cause of gender development in the country is caused by their poor perception of government's interest.

A further reinforcement to the finding was emphasized by the fact that journalists who are knowledgeable about gender mainstreaming issues tend to report the issues more than those who are not better informed. This finding empirical evidence obviously compels an examination of journalists' attitudes towards the ideology of gender mainstreaming reporting thus bringing forth null hypothesis three as: Nigerian journalists are not favorably disposed towards the ideology of gender mainstreaming reporting.

This hypothesis obtained statistical support at chi-square $\left(\mathrm{x}^{2}\right)$ calculated value of 9.23 which is lesser than the $\mathrm{x}^{2}$ table value of 9.49. Again, this finding offers an explanation to the gross under representation and poor portrayal of women in the media confirmed by sources in our literature and fall in line with the permissive subjectivism of the gatekeeping theory which forms part of the theoretical base of this study. This means that the journalists are not favourably inclined to the ideology of gender mainstreaming, inasmuch as our empirical evidence confirms the claim that they have significant knowledge of the issues. It therefore, means that in selecting what to report, how to report it, and the language to use, the journalists' do not make considerations for including obvious implications of the gender mainstreaming in their reporting. The implications of which have become necessary, following the with emphasis on gender approach to develop- 
ment (GAD) which brings to bear the ethical need for journalists to appreciate the plight of women by promoting gender balance in media contents. In this vein, it becomes pertinent to reason that before they can perform the present task, they should begin to change their mindsets and attitudes in favour of women rights agenda. Unfortunately, this has not been the case, as established by the above empirical evidence, and the position of our literature.

Other results equally confirm the non-chalant attitude of our journalists towards gender mainstreaming. For instance, data revealed that majority of the respondents tilted towards rejection as to whether the seeming situation of women discrimination in Nigeria is a cause to worry. More so, their position was clear, as to the question on if journalists give attention to women's interests in their reportage of gender mainstreaming issues more than men's interests. To this, majority of the respondents showed disagreement.

Meanwhile, in examining the influence of the dominant form of coverage of gender mainstreaming issues, hypothesis four was stated in its null form thus: The dominant form of reporting of gender mainstreaming issues by journalists does not influence their perception of the phenomenon. This hypothesis was rejected at $\mathrm{x}^{2}$ calculated value of 18.35 which is greater than $\mathrm{x}^{2}$ table value of 3.84, leading to the upholding of its alternate. In other words, the nature of gender mainstreaming issues you read or write most of the time influences your perception of the ideology, as established by the above result.

This finding is important, particularly when we recall that in journalism parlance, news only aim at giving information about an issue, unlike features or documentaries that could afford reporters the opportunity of interpretation or rather doing a gender analysis which can positively impact on the minds of the audience in favour of women rights agenda. And since their dominant form of coverage is news, which does not give interpretations to the issues, there is little likelihood that their mindsets will begin to favour gender mainstreaming or perhaps women's rights agenda. This is in line with Gallagher's (2010:5) submission that women's lives should be taken more seriously and also confirm the position of the literature review about the improving visibility and participation of women in the country's mass media.

It is important to note therefore, that the above finding does not augur well for societal growth, particularly when majority of the journalists have acknowledge the fact that increased mass media reportage will influence citizens appreciation of the issues.

Apart from the mere revelation of their dominant form of coverage of the issues, perhaps another deducible interpretation may be that Nigerian journalists lack commitment to the cause of gender mainstreaming.

\section{Conclusion}

With this development, therefore, it is obvious that the task ahead for the journalists, necessitated by the current global consensus of gender mainstreaming is not an easy one. More so, when our statistics further confirm that the journalists 
do not consider gender mainstreaming issues important enough, as to attract editorial comments or in depth feature stories, thereby making straight news report their dominant form of approach. The implication is that they lack commitment to the cause of gender mainstreaming which brings to bear on their ethical need to appreciate the plight of women, by shaping gender realities of the moment and promoting gender balance in media reports. This position agrees with the principles of the watchdog concept that sees the protection of public interest by the media as an obligation and/or ethical responsibility. Women constitute almost half of the population in Nigeria, and at least their interests and aspirations should deserve the protection of the mass media. Therefore, to deny them the right to communicate, to speak, and to be listened to in public space; especially the mainstream media, is against fundamental human right, and the principles of democracy, and sustainable national development efforts, as confirmed by the findings.

\section{Recommendations}

In view of the findings, the study recommends the following:

In ensuring that journalists begin to appreciate their ethical responsibility towards the cause of gender mainstreaming, there is need for them to be properly sensitized. The sensitization should be geared towards making them appreciate their unique role as watchdogs of public's interest, and also appreciate the plight of women who make up almost half of the population of Nigerian's patriarchal system. Moreover, there is need for them to also be sensitized on the necessary skills to use in order to adequately cover the roles and interests of women in reporting gender related issues. This sensitization will also extend to media owners because they are the people involved with hiring of staff. When media owners and practitioners are effectively sensitized, they will appreciate the need to ensure that people being employed as journalists would have undergone training in the area of gender-sensitivity in news reporting.

Again, in making journalists recognize the importance of media to the advancement of women and humanity, there will be need to strengthen advocacy and also move beyond the media organizations to media associations, since they are the umbrella body that can take decisions worthy of influencing media and editorial policies which, can facilitate gender sensitive and balanced reporting. Any policy guide line in this direction should be aimed at promoting quality journalism in terms of ethics and news values. In so doing, journalists should be sensitized to appreciate that fair gender portrayal is a professional and ethical aspiration, similar to respect for accuracy, fairness and honesty; and worthy of promoting content that can attract new audiences who, in many parts of the world, are composed of women and, who presently are underserved.

Also, the task to make government recognize need for practical demonstration of genuine to the cause of gender mainstreaming will require the building of partnership between civil society groups in the area of media rights agenda, the 
mass media and government parastatals responsible for gender issues. It will be a coalition of networks aimed at monitoring and following up actions on government initiatives aimed at removing socio-cultural, political, legal, or economic factors which prevent women from enjoying their fundamental human rights. In so doing, the journalists and ordinary citizens of Nigeria will be truly convinced that government is actually interested in the cause.

\section{Conflicts of Interest}

The authors declare no conflicts of interest regarding the publication of this paper.

\section{References}

Akpalu, E., Aboagye, E., \& Derbyshire (2002). Gender Mainstreaming: Emerging Seasons from Ghana. DFID Reports.

Ana, I. (2008). Gender Mainstreaming Imperative for Poverty Alleviation. In National Conference of Nigerian Institute of Management.

Baran, S. (2009) Introduction to Mass Communication Media Literacy and Culture. Houston, TX: Mayfield Publishing Company.

Defleur, M., D’Antonio, W., \& Defleur, B. (1971) Sociology: Man in Society. Glenview, IL: Scott Foresman and Company Ltd.

Gallagher, M. (2005). Beijing's Legacy for Gender and Media. Media Development, Journal of the World Association for Christian Communication, 52, 3-7.

Gallagher, M. (2010). Women's Human and Communication Rights. Media Development, Journal of the World Association for Christian Communication, 57, 3-6.

GMMP (2000). Global Report. http://www.whomakesthenews.org

GMMP (2010). Global Report. http://www.whomakesthenews.org

Goldberg, B. (2002). BIAS-A CBS Insider Exposes How the Media Distort the News. Washington DC: Regency Publishing Inc.

Lee, P. (2006). Can the Media Be a Sanctuary for Human Rights? Media Development, Journal of the World Association for Christian Communication, 53, 3-6.

MacBride, S. et al. (1980). Many Voices, One World, Communication and Society, Today and Tomorrow. New York: UNESCO.

Macharia, S. (2010). National Framework. http://www.whomakesthenews.org

Made, P. (2004). Women Creating Spaces of Their Own. Media Development Journal, 52, 3-6.

Mohr, L. (2008). Communication Poverty: A Rights-Based Approach. Media Development Journal of WACC, 55, 8-11.

NUJ (2010). Nigerian Union of Journalist Newsletter.

Nwanna, O. C. (2008). Introduction to Educational Research. Ibadan: Heinemann Educational Books (Nig) Ltd.

Obasi, I. N. (1999). Research Methodology in Political Science. Enugu: Academic Publishing Company.

Oji, N. (2008). Gender Mainstreaming; Poverty Alleviation and Sustainable Human Development. In I. Nwosu, N. Fab-Ukozor, \& L. Nwodu (Eds.), Communication for Sustainable Human Development (pp. 124-134). Enugu: African Council for Communica- 
tion Education.

Okunna, C. S. (2002). A Quick Look at Development Communication. In C. Okunna (Ed.), Teaching Mass Communication: A Multidimensional Approach. Enugu: New Generation Books.

Omenugha, K., \& Adum, A. (2008). Nigeria's Spiral of Silence: Can the Media Build a Culture of Peace? Media Development Journal of WACC, 55, 50-53.

Tacchi, J. (2008). Voice and Poverty. Media Development Journal of WACC, 55, 12-15.

UN's Press Release, WOM/1495 (2005). Commission on the Status of Women. 